\title{
Maternal Feeding Goals and Restaurant Menu Choices for Young Children
}

\author{
Sarah E. Domoff, PhD, Allison Kiefner-Burmeister, PhD, \\ Debra A. Hoffmann, MA, and Dara Musher-Eizenman, $\mathrm{PhD}^{3}$
}

\section{Abstract}

Background: Childhood obesity remains a major public health issue. One recent effort to improve the obesogenic environment is mandating that restaurants provide calorie and other nutritional content on menus. Little is known about whether maternal feeding $\vec{F}$ for young children is influenced by calorie disclosure on menus. This study examined (1) whether maternal feeding goals associate with mothers' food selections for their young children and (2) whether mothers change entrée and side selections for their children when calories/fat grams are listed on menus.

Methods: One-hundred seventy mothers of children ages of 3-6 years participated in an online survey. Most participants identified as white $(76.5 \%)$, with a mean BMI of 25.68 (standard deviation $=5.94$ ). Mothers were presented two menus (one with and one without calorie/fat information).

Results: The goal of feeding for the child's familiarity with the food was significantly associated with mothers' selection of original side dish and entrées, with greater endorsement of this goal associated with choosing high-calorie/-fat sides and entrées. Feeding for natural content was associated with mothers' selection of original entrée, with greater endorsement of this goal associated with choosing E⿱

Conclusions: Maternal feeding goals are associated with mothers' selection of entrée and side dishes on restaurant menus. Results from this study suggest that menu labeling of calories and fat grams may influence entrée choices by mothers. Targeting mothers' feeding goals and labeling restaurant menus may improve the diets of young children.

\section{Introduction} and $7 \%$ for men. ${ }^{3}$ Daily energy intake continues to rise, with an increase of 229 calories per day between the time points of 1994-1998 and 2003-2006. ${ }^{4}$ The rise in calories consumed has been attributed, in part, to increased food consumption outside the home, which almost doubled from 1977 to 1995 . $^{1}$ The fast food industry, in particular, has been criticized for contributing to obesity. Individuals who eat fast food consume more calories from fat and larger portions than when they eat at home. ${ }^{5-9}$

Consumers significantly underestimate the calories, fat, and sodium in unhealthy food, but are more accurate with healthy food. ${ }^{10-12}$ Thus, public health efforts have attempted to better inform consumers about the foods they eat by mandating restaurants to provide calorie content on menus. In 2008, New York City required restaurant chains with more than 15 locations to display calorie information on their menus. ${ }^{13}$ Shortly after, several other states and locales followed suit. ${ }^{13}$ Recent federal law now requires vending machines and restaurants with over 20 locations to disclose nutritional information. ${ }^{14}$ The assumption is that providing nutritional information will help people make healthier choices.

Despite these policy changes, choosing lower-calorie options when given calorie information occurs either not at all or for only some individuals. In a study of children (ages 6-11 years) and their parents, Tandon and colleagues found that the average calories purchased for children did not change after implementation of menu labeling at fast food restaurants. ${ }^{15}$ Similarly, in a study of adolescents, more than $80 \%$ of the sample did not change their meal orders when calories were presented. ${ }^{16}$ Bates and colleagues found that when items are consistent with expectations, calorie disclosure does not change purchase intentions. ${ }^{10}$ But, when

\footnotetext{
'Center for Human Growth and Development, University of Michigan, Ann Arbor, MI.

${ }^{2}$ Department of Psychology, The University of Findlay, Findlay, $\mathrm{OH}$.

${ }^{3}$ Department of Psychology, Bowling Green State University, Bowling Green, $\mathrm{OH}$.
} 
disclosed calories are inconsistent with consumers' expectations, purchase intentions decrease significantly. ${ }^{10}$ Finally, when motivation for healthy eating is low, disclosing calories has no effect; but when it is high, consumers are less likely to select unhealthy items. ${ }^{10}$

Although research has examined calorie disclosure and food choice in older children, ${ }^{15}$ adolescents, ${ }^{16}$ and adults, ${ }^{11,17}$ few studies have examined the role of calorie disclosure on young children's food choice. Little is known about the role menu labeling may have on maternal feeding of children ages 3-6 years. Two studies in samples of parents and their young children (ages 3-6 years) demonstrate mixed results. Tandon and colleagues found that parents who received a McDonald's menu with caloric information chose food for their child that was, on average, 100 calories less than parents who did not receive the caloric information. ${ }^{18}$ Conversely, Holmes and colleagues found that presenting caloric information did not decrease . the total calories in foods chosen by parents in a real restaurant. ${ }^{19}$ Clearly, more research is needed to identify I factors that influence menu choices by mothers for their young children. One important factor contributing to . mothers' menu selections could be feeding goals, which are associated with feeding practices. ${ }^{20}$ Healthy feeding goals may especially support healthy food selection when nutritional information is presented on menus.

In the present study, we predicted that maternal feeding E. goals would be associated with mothers' food choices for on their child from a menu that is presented without nutritional information. We also predicted that more mothers would choose lower-calorie and -fat options on the labeled 흘 menus than on the unlabeled menus.

\section{Methods}

\section{Participants and Procedure}

Participants were recruited through Mechanical Turk, an online Amazon workforce, and provided informed consent before participation. Participants received 75 cents for completing the 20 -minute online survey. The University Human Subjects Review Board approved the procedures. $\triangle$ To participate, individuals had to (1) be a US resident, (2) be the mother and primary caretaker of a child 3-6 years of age, and (3) speak English fluently. The sample consisted of 170 participants (16 additional participants were excluded for not meeting eligibility requirements). The sex of the child for whom the mother was responding was nearly evenly distributed, with $45.2 \%$ males and $54.8 \%$ females. Most participants identified as white $(n=132 ; 76.5 \%)$, with an annual income less than $\$ 75,000(n=127 ; 74.7 \%)$. Mothers' BMI $\left(\mathrm{kg} / \mathrm{m}^{2}\right)$ was calculated from self-reported height and weight (mothers' BMI: mean $[\mathrm{M}]=25.68$; standard deviation $[\mathrm{SD}]=5.94)$. Child BMI percentiles were calculated based on standard growth charts, ${ }^{21}$ also based on mothers' report (child BMI percentile: $\mathrm{M}=67.55 \%$; $\mathrm{SD}=37.23 \%)$. The vast majority of the sample $(97.6 \%)$ received a high school degree/GED (General Educational
Development) or higher (e.g., some college courses, college degree, or postgraduate degree). Frequency of eating at fast food restaurants was distributed in the sample: In the past week, $35.5 \%$ of participants reported not eating at a fast food restaurant; $57.4 \%$ reported eating at these types of restaurants one to three times; and $6.9 \%$ reported eating at fast food restaurants four or more times.

\section{Measures}

Menu choices. Two restaurant menus were generated (see Tables 1 and 2) to assess what mothers choose to feed their children. The menus showed identical choices, one with nutritional information (calories and fat grams) and one without nutritional information. Participants were asked, "If you are eating at a restaurant and are given the following fixed-price menu for this child, what would you order? Select one entrée and one side dish." In this study, an entrée could also be understood as a "main dish." To be consistent with the language used in the survey, we will use the term "entrée" to capture that menu option. Lower-calorie/-fat foods were coded as " 0 " and higher-calorie/-fat foods were categorized as " 1 " for analyses. Each participant was first shown a menu without nutritional information and could not return to this original menu after selecting food choices. Later in the study (i.e., after several additional measures), the mothers received an identical menu, this time with calories and fat grams listed per item.

Feeding goals. Maternal feeding goals were assessed using a modified Food Choice Questionnaire. ${ }^{22}$ Mothers rated how important it is to feed their child according to certain goals. Six goals were examined (i.e., Health, Child Mood, Sensory Appeal, Natural Content, Child Weight Control, and Familiarity of Food). For example a Health feeding goal item was: "It is important to me that the foods I feed my child contain a lot of vitamins and minerals". A Natural Content feeding goal item was: "It is important to me that the foods I feed my child contain no artificial ingredients." Response options ranged from 1 (not at all) to 5 (completely), with higher scores indicating higher endorsement of the goal. Subscale reliability ranged from $\alpha=0.77$ to 0.84 .

\section{Table I. Menu without Calorie and Fat Information}

\begin{tabular}{l|l} 
Side item & \multicolumn{1}{c}{ Entrée } \\
French fries & Grilled chicken \\
\hline Mixed vegetables & Mac \& cheese \\
\hline Mozzarella sticks & Baked fish \\
\hline Sliced fruit & Chicken nuggets \\
\hline Bread sticks & Vegetable and rice stir fry \\
\hline House salad & Cheeseburger \\
\hline
\end{tabular}




\section{Table 2. Menu with Calorie and Fat Information}

\begin{tabular}{|c|c|c|c|}
\hline Side item & $\begin{array}{l}\text { Nutritional } \\
\text { information }\end{array}$ & Entrée & $\begin{array}{l}\text { Nutritional } \\
\text { information }\end{array}$ \\
\hline French fries ${ }^{b}$ & $231 \mathrm{cal}, 11.5 \mathrm{~g} \mathrm{fat}$ & Grilled chicken ${ }^{\mathrm{a}}$ & $210 \mathrm{cal}, 8 \mathrm{~g} \mathrm{fat}$ \\
\hline Mixed vegetables $^{\mathrm{a}}$ & $35 \mathrm{cal}, 0 \mathrm{~g}$ fat & Mac \& cheese ${ }^{b}$ & $490 \mathrm{cal}, 30 \mathrm{~g}$ fat \\
\hline Mozzarella sticks ${ }^{b}$ & $215 \mathrm{cal}, \mathrm{II} \mathrm{g} \mathrm{fat}$ & Baked fish ${ }^{\mathrm{a}}$ & $180 \mathrm{cal}, 9 \mathrm{~g}$ fat \\
\hline Sliced fruit ${ }^{\mathrm{a}}$ & $35 \mathrm{cal}, 0 \mathrm{~g}$ fat & Chicken nuggets $^{\mathrm{b}}$ & $275 \mathrm{cal}, 17 \mathrm{~g}$ fat \\
\hline Bread sticks ${ }^{b}$ & $156 \mathrm{cal}, 6 \mathrm{~g}$ fat & Vegetable and rice stir fry ${ }^{a}$ & $140 \mathrm{cal}, 0 \mathrm{~g}$ fat \\
\hline House salad ${ }^{a}$ & $60 \mathrm{cal}, \mathrm{Ig}$ fat & Cheeseburger ${ }^{\mathrm{b}}$ & $330 \mathrm{cal}, \mathrm{l} 4 \mathrm{~g} \mathrm{fat}$ \\
\hline
\end{tabular}

aLower-calorie/-fat foods were coded as "0" and bhigher-calorie/-fat foods were categorized as "I" in the analyses.

玄

\section{Statistical Analysis}

Preliminary analyses were conducted to identify covariates, which were later controlled (i.e., frequency of attending fast food restaurants, parent age, and child gender). Frequencies of mothers' menu selections with and without I calorie labeling were calculated, and cross-tabulation analysis, with McNemar's test, was conducted to examine \%. whether frequencies significantly differed by menu. Logistic regressions were conducted to examine the associ-

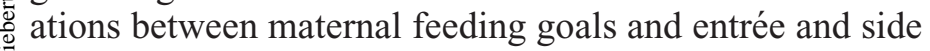
dish selection.

\section{Results}

Menu Selection without Calorie Labeling

and Maternal Feeding Goals

When mothers viewed the menus without nutritional $\stackrel{i}{i}$ information, $34.1 \%(n=58)$ chose a high-calorie, high-fat side for their child and $58.2 \%(n=99)$ chose a high-calo$\sum$ rie/-fat entrée (see Table 3).

Logistic regressions were calculated with side and entrée choice as the dependent variables and maternal feeding goals as the independent variables. Covariates were entered into the first step of these models, and all feeding gु goals were entered into the second step to reduce multicollinearity (see Table 4). For the side choice, the feeding ڤo goal block was significantly associated with participants' food selection, beyond that of the covariates. Specifically, feeding for food familiarity was significantly associated with choosing high-calorie/-fat side dishes. Approximately $25 \%$ of the variance was explained by the covariates and maternal feeding goals. The model had a higher specificity than sensitivity, with $86.9 \%$ correct prediction of choosing the lower-calorie/-fat options versus $43.6 \%$ correct prediction of side choices that were higher-calorie/-fat.

For the entrée choice, the feeding goal block significantly associated with participants' entrée selection, beyond that of the covariates (see Table 5). Feeding for natural content was significantly associated with choosing lower-calorie/-fat entrées, whereas food familiarity was significantly associated with choosing higher-calorie/-fat entrées. Approximately $25 \%$ of the variance was explained by the covariates and maternal feeding goals. Fast food frequency and maternal feeding goals accurately predicted approximately $70 \%$ of the entrées chosen. This model had a higher sensitivity than specificity, with $78.6 \%$ correct prediction of choosing the higher-calorie/-fat options versus $57.7 \%$ correct prediction of lower-calorie/-fat entrée choices.

\section{Menu Selection With Calorie and Fat Labeling}

When menus were presented with calorie and fat labeling, significantly fewer mothers chose high-calorie/fat entrées for their young children $(n=84$ [49.4\%]; McNemar's test exact significance $=0.004$; see Table 3). Very few participants changed their side option from a

Table 3. Frequency of Side and Entrée Choices for Menu without Nutritional Information

\begin{tabular}{|c|c|c|c|c|c|}
\hline \multirow[b]{2}{*}{ Side option } & Not labeled & Menu labeled & \multirow[b]{2}{*}{ Entrée option } & Not labeled & Menu labeled \\
\hline & Frequency (\%) & Frequency (\%) & & Frequency (\%) & Frequency (\%) \\
\hline French fries & $43(25.3)$ & $33(19.5)$ & Grilled chicken & $47(27.6)$ & $60(35.3)$ \\
\hline Mixed vegetables & $30(17.6)$ & $35(20.7)$ & Mac \& cheese & $36(2 \mid .2)$ & $18(10.6)$ \\
\hline Mozzarella sticks & $12(7.1)$ & II (6.5) & Baked fish & $9(5.3)$ & II (6.5) \\
\hline Sliced fruit & $72(42.4)$ & $70(41.4)$ & Chicken nuggets & $49(28.8)$ & $48(28.2)$ \\
\hline Bread sticks & $3(1.8)$ & $8(4.7)$ & Vegetable and rice stir fry & $15(8.8)$ & $15(8.8)$ \\
\hline House salad & $10(5.9)$ & $12(7.1)$ & Cheeseburger & $14(8.2)$ & $18(10.6)$ \\
\hline
\end{tabular}




\begin{tabular}{|c|c|c|c|}
\hline Predictors & B & SE (B) & Wald \\
\hline Mother age & $0.01 * *$ & .00 & 7.67 \\
\hline Child gender ${ }^{b}$ & $-0.72^{*}$ & .38 & 3.62 \\
\hline Health feeding goal & $-0.64^{*}$ & .38 & 2.85 \\
\hline Child mood feeding goal & -0.11 & .25 & 0.20 \\
\hline Sensory appeal feeding goal & -0.05 & .31 & 0.03 \\
\hline Natural content feeding goal & -0.21 & .25 & 0.66 \\
\hline Child weight control feeding goal & -0.22 & .23 & 0.94 \\
\hline Familiarity of food feeding goal & $0.80 * *$ & .29 & 7.75 \\
\hline Model $\chi^{2}$ & $\chi^{2}(8)=20.29 * *$ & & \\
\hline Nagelkerke $R^{2}$ & $0.25 * *$ & & \\
\hline
\end{tabular}

${ }^{\mathrm{a}} 0$ : lower calorie/fat; I: higher calorie/fat.

b0: male; I: female.

$* p<0.10 ; * * p<0.01$.

SE, standard error.

high-calorie/-fat option to a lower-calorie choice $(n=6$; McNemar's test exact significance $=0.332$ ).

\section{Discussion}

This study investigated the influence of menu calorie information on mothers' feeding of young children. An increasing number of restaurants now display calorie information on menus. This trend toward rising food industry disclosure is accompanied by questions of the policy's

Table 5. Logistic Regressions Examining Associations between Maternal Feeding Goals and Entrée Choices ${ }^{\mathrm{a}}$ for Young Children

\begin{tabular}{l|c|c|c} 
Predictors & B & SE (B) & Wald \\
\hline Fast food frequency & 0.40 & 0.29 & I.86 \\
Health feeding goal & -0.58 & 0.35 & 2.65 \\
Child mood feeding goal & -0.09 & 0.23 & 0.15 \\
Sensory appeal feeding goal & 0.30 & 0.28 & I.I7 \\
Natural content feeding goal & $-0.74^{* *}$ & 0.26 & 8.21 \\
Child weight control feeding goal & -0.01 & 0.21 & 0.00 \\
Familiarity of food feeding goal & $0.55^{*}$ & 0.24 & 5.25 \\
\hline Model $\chi^{2}$ & $\chi^{2}(7)=34.36^{* *}$ & & \\
Nagelkerke $R^{2}$ & $0.25^{* *}$ & & \\
\hline
\end{tabular}

${ }^{\mathrm{a}}$ 0: lower calorie/fat; I: higher calorie/fat.

$* p<0.05$; ** $p<0.0$ I.

$\mathrm{SE}$, standard error. effectiveness. This study used two menus (i.e., with and without calorie and fat information) to assess differences in foods selected for children 6 years and younger.

When mothers chose an entrée (and side) for their child from a fixed price menu with no calorie or fat information, $58.2 \%$ of mothers chose high-fat and high-calorie entrées (34.1\% chose high-fat and high-calorie sides). Further, maternal feeding goals predicted meal and side choices, with feeding for familiarity predicting higher-calorie and -fat side and entrée options. Endorsement of natural content as a feeding goal was associated with lower-calorie and -fat entrée selections.

When the menu was presented to mothers again with calorie information, significantly fewer mothers chose a high-calorie entrée. An implication of this study is that presenting calorie and fat information on restaurant menus may be effective for changing certain aspects of maternal feeding (e.g., entrées), but not others (e.g., sides). An alternative explanation, however, is that the majority of mothers $(65.9 \%)$ had already selected lower-calorie side dish options for their children, leaving less room for change. There is also a possibility that individual differences in receptiveness to menu labeling could factor into which mothers chose healthier options. It would be important for future research to identify which mothers are influenced by nutrition information on restaurant menus (e.g., those with specific feeding goals, with certain demographic characteristics, as well as child factors, such as temperament and food fussiness).

This study has limitations that should be addressed in future studies. First, we did not measure mothers' tendency to respond in socially desirable ways. It is also possible that participants who chose to participate in this study were more interested in their own feeding behaviors, which could have led to a selection bias. Connected to this limitation are the relatively homogenous demographic characteristics of the current sample. Most of the sample was Caucasian, and nearly all had a high school degree or higher. Research indicates that adults from low-income and minority groups do not purchase fewer calories after implementation of menu labeling, ${ }^{23}$ and that there are other distinct barriers that may influence utilization of nutritional information on menus in these groups. ${ }^{24}$ Thus, it may be the case that mothers from low-income or minority groups also experience barriers to utilizing nutritional information on these menus when choosing food for their young children. Future research should seek to replicate this study in diverse samples of low-income families to address this gap in the research.

Second, it would be informative to include qualitative items asking participants their reason for having chosen the menu items. It is possible that food aversions and pickiness could have contributed to the menu choices and not disregard of nutritional content. It is important to note that we did not assess the presence of developmental disorders in the children of the mothers surveyed in this study. This is a limitation, in that children with developmental disorders, 
such as autism spectrum disorders, have higher rates of food selectivity, compared to typically developing children. ${ }^{25}$ Thus, it is possible that, for mothers of children with picky eating, menu labeling may not facilitate different food choices. Future research should examine the role of picky eating and food selectivity in mothers' utilization of nutritional information on menus, as well as whether these findings are replicated in mothers of children with developmental disorders. Finally, measurement of feeding decisions was based only on self-report; future studies could measure actual food purchases.

\section{Conclusions}

त्ञ

In summary, results from this study suggest that menu labeling of calories and fat grams may influence mothers' 的 entrée choices, but that maternal feeding goals are also important to consider. Taken together, it appears that both targeting mothers' feeding goals and menu labeling may $\stackrel{\overrightarrow{0}}{\mathrm{i}}$ improve the diets of young children.

\section{Author Disclosure Statement}

No competing financial interests exist.

. Lin BH, Frazao E, Guthrie. Away-from-home foods increasingly important to quality of american diet. Agriculture Information Bulletin No. 479. USDA: Washington, DC, 1999.

2. USDA. Profiling food consumption in America. Agriculture fact book 2001-2002. USDA: Washington, DC, 2003.

3. CDC. Trends in intake of energy and macronutrients-United States, 1971-2000. MMWR Morb Mortal Wkly Rep 2004;53: $80-82$.

4. Duffey KJ, Popkin BM. Energy density, portion size, and eating occasions: Contributions to increased energy intake in the United States, 1977-2006. PLoS Med 2011;8:e1001050.

5. Bowman SA, Gortmaker SL, Ebbeling CB, et al. Effects of fastfood consumption on energy intake and diet quality among children in a national household survey. Pediatrics 2004;113:112-118.

6. Bowman SA, Vinyard BT. Fast food consumption of US adults: Impact on energy and nutrient intakes and overweight status. Coll Nutr 2004;23:163-168.

7. Nielsen SJ, Popkin BM. Patterns and trends in food portion sizes, 1977-1998. J Am Med Assoc 2003;289:450-453.

8. Paeratakul S, Ferdinand DP, Champagne CM, et al. Fast-food consumption among US adults and children: Dietary and nutrient intake profile. J Am Diet Assoc 2003;103:1332-1338.

9. Young LR, Nestle M. Expanding portion sizes in the US marketplace: Implications for nutrition counseling. $\mathrm{J} \mathrm{Am} \mathrm{Diet} \mathrm{Assoc}$ 2003;103:231-240.

10. Bates K, Burton S, Howlett E, et al. The roles of gender and motivation as moderators of the effects of calorie and nutrient information provision on away-from-home foods. $J$ Consum Aff 2009;43:249-273.
11. Burton S, Creyer EH, Kees J, et al. Attacking the obesity epidemic: The potential health benefits of providing nutrition information in restaurants. Am J Public Health 2006;96:1669-1675.

12. Tangari AH, Burton S, Howlett E, et al. Weighing in on fast food consumption: The effects of meal and calorie disclosures on consumer fast food evaluations. $J$ Consum Aff 2010;44:431-462.

13. Center for Science in the Public Interest. Nutrition labeling in chain restaurants, state and local laws/bills/regulations: 2009-2010. 2010. Available at http://cspinet.org/new/pdf/ml_bill_summaries_09.pdf Last accessed January 13, 2015.

14. US Food and Drug Administration. Overview of FDA labeling requirements for restraurants, similar retail food establishments and vending machines. 2014. Available at www.fda.gov/Food/ IngredientsPackagingLabeling/LabelingNutrition/ucm248732.htm Last accessed January 13, 2015.

15. Tandon PS, Zhou C, Chan NL, et al. The impact of menu labeling on fast-food purchases for children and parents. Am J Prev Med 2011;41:434-438.

16. Yamamoto JA, Yamamoto JB, Yamamoto BE, et al. Adolescent fast food and restaurant ordering behavior with and without calorie and fat content menu information. J Adolesc Health 2005;37:397-402.

17. Roberto CA, Larsen PD, Agnew H, et al. Evaluating the impact of menu labeling on food choices and intake. Am J Public Health 2010;100:312.

18. Tandon PS, Wright J, Zhou C, et al. Nutrition menu labeling may lead to lower-calorie restaurant meal choices for children. Pediatrics 2010;125:244-248.

19. Holmes AS, Serrano EL, Machin JE, et al. Effect of different children's menu labeling designs on family purchases. Appetite 2013;62:198-202.

20. Kiefner-Burmeister AE, Hoffmann DA, Meers MR, et al. Food consumption by young children: A function of parental feeding goals and practices. Appetite 2014;74:6-11.

21. Kuczmarski RJ, Ogden CL, Grummer-Strawn LM, et al. CDC growth charts: United States. Adv Data 2000;(314):1-27.

22. Steptoe A, Pollard TM, Wardle J. Development of a measure of the motives underlying the selection of food: The food choice questionnaire. Appetite 1995;25:267-284.

23. Elbel B, Kersh R, Brescoll VL, et al. Calorie labeling and food choices: A first look at the effects on low-income people in New York City. Health Aff (Millwood) 2009;28:w1110-w1121.

24. Schindler J, Kiszko K, Abrams C, et al. Environmental and individual factors affecting menu labeling utilization: A qualitative research study. J Acad Nutr Diet 2013;113:667-672.

25. Bandini LG, Anderson SE, Curtin C, et al. Food selectivity in children with autism spectrum disorders and typically developing children. J Pediatr 2010;157:259-264.

Address correspondence to:

Sarah E. Domoff, PhD

Research Fellow

Center for Human Growth and Development University of Michigan 300 North Ingalls Street 10th Floor Ann Arbor, MI 48109-5406

E-mail:sdomoff@umich.edu 